\title{
REVIEW OF DIFFERENT TECHNIQUES TO STUDY THE INTERACTIONS BETWEEN COKE AND PITCH IN ANODE MANUFACTURING
}

\author{
Duygu Kocaefe ${ }^{1}$, Arunima Sarkar ${ }^{1}$, Shipan Das ${ }^{1}$, Salah Amrani ${ }^{1}$, Dipankar Bhattacharyay ${ }^{1}$, Dilip Sarkar ${ }^{1}$, Yasar Kocaefe $^{1}$, \\ Brigitte Morais², Marc Gagnon ${ }^{2}$ \\ ${ }^{11}$ Centre universitaire de recherche sur l'aluminium (CURAL), University of Quebec at Chicoutimi, 555, boul. De l’Université, Chicoutimi, \\ Quebec, Canada G7H 2B1 \\ ${ }^{2}$ Aluminerie Alouette inc., 400, Chemin de la Pointe-Noire, C.P. 1650, Sept-Îles, Quebec, Canada, G4R 5M9
}

Keywords: Coke, Pitch, Image Analysis, Optical Microscopy, SEM, XRD, XPS

\begin{abstract}
The quality of carbon anodes, consumed in electrolysis during the primary aluminum production, has an important impact on the electrolytic cell performance. Coke and pitch are the raw materials used in anode manufacturing. The raw material properties and the process parameters during production determine the anode quality. A plant receives these materials from different sources, and the variability in their properties is usually a major concern during anode production. The interaction between coke and pitch influences strongly the anode properties. Study of coke and pitch individually as well as the interactions between them (using different techniques (spectroscopic, optical, etc.) such as XRD, FTIR, XPS, SEM helps identify their compatibility. Each technique gives information on different aspects of the raw materials. In this article, the use of a number of these techniques for studying coke, pitch, and their interactions will be discussed. Results will be presented for a number of cases.
\end{abstract}

\section{Introduction}

The anodes supply the carbon required for the reduction of alumina by electrolysis in the Hall-Héroult process. Though the minimum theoretical carbon consumption is $0.334 \mathrm{~kg} \mathrm{C} / \mathrm{kg} \mathrm{Al}$, yet due to cell current efficiency and various losses, the consumption is typically over $0.4 \mathrm{~kg} \mathrm{C} / \mathrm{kg} \mathrm{Al}$. Carbon anodes are an important part of the primary aluminum production cost [1]. The minimization of excess consumption of anodes is one of the key industrial goals. Quality of anode is directly related to the production cost, energy consumption, and emission of greenhouse gases.

Anodes are produced mainly using calcined petroleum coke and coal tar pitch as well as the recycled green and baked anodes and anode butts. Petroleum coke constitutes about $2 \%$ of the overall production of an oil refinery [2]. Thus, its quality is not necessarily a major concern of the producers. Moreover, the mechanical and physical properties of coke depend on the crude oil, processes within the refineries, and coke calcination conditions. Coal tar pitch, which is a binder for the granular material, has been described by the international committee for characterization and terminology of carbon as a residue produced by distillation or heat treatment of coal tar. Similar to coke, the quality of this by-product is crucial for the anode quality. Thus, the production of good quality anodes with the available raw materials has become a challenge for the industries.

Understanding the coke-pitch interaction during the fabrication of anodes will help improve the prebaked anode quality. Green anodes are fabricated by mixing calcined coke with pitch at elevated temperature (usually $50^{\circ} \mathrm{C}$ more than the softening point of pitch) and compacted using a press or a vibrocompactor. The green anodes are baked at high temperatures during which the carbonization of pitch takes place [3]. Carbonization helps in binding coke particles together and, consequently, increases the electrical conductivity.

Additional carbon losses occur due to air and carbon dioxide reactivities. The air that reaches the anode surface by infiltrating the alumina cover results in the combustion of carbon near the top of the anode. The loss depends on the anode temperature at the top (which is a function of the anode thermal conductivity), impurities such as vanadium, porosity, etc. Carbon dioxide reactivity occurs at the interface where anode is in contact with the electrolyte in the bath. Again, the impurities, porosity, wettability of anode by the electrolyte, etc. play an important role. Also, one of the problems is the failure of the structural integrity of an anode by the preferential reaction of the carbonized pitch (preferential oxidation due to the differences in coke and carbonized pitch reactivities). Particles of coke break apart from the anode and fall into the bath; this is called dusting. Study of coke-pitch interactions help understand all these phenomena. According to literature, the difference between the crystalline lengths of petroleum coke and the carbonized pitch is important for the reactivity [4].

It is also a common practice in industry to mix different stocks of coke or pitch to obtain desired final properties or to meet various norms (such as maintaining sulfur emissions below a target value). However, these mixtures of coke or pitch may not be necessarily compatible. Thus, coke mixtures, pitch mixtures, and the cokepitch interaction of their mixtures need to be studied to determine their compatibility.

Some of the characterization tests are carried out on either coke or pitch. The interaction between coke and pitch could be chemical, physical or both. These interactions can also be studied using various techniques. Different tests reveal different types of information, some reinforcing one another and some complementing each other.

Wettability of coke by pitch determines the quality of bonding between these two components and thereby greatly affects the final anode properties. Mirtchi et al [5] observed that increase in temperature can increase wetting. A number of researchers [3, 610] have reported that increase in time also increases wetting of coke by pitch. A systematic study is necessary to further understand the wetting of coke by pitch.

Researchers have identified various properties of coke and pitch that can control the coke-pitch interactions. Softening point, coking value, chemical composition, surface tension, and viscosity of pitch and particle size distribution, texture, surface functional groups, and porosity of coke [8] are of chief interest. Standard methods 
have been developed to measure some of the properties (such as the softening point, crystalline length, and pitch viscosity); however, other factors such as surface functional groups are not easy to determine and usually require analyses at the microscopic level. This work focuses on the application of various tools to probe into the details of coke-pitch interactions leading to the formation of a good quality anode.

\section{Analysis Methods}

As mentioned previously, the role of pitch is to bind the coke particles together. The pitch not only fills the intra and intergranular pores of the coke particles, but also ensures the adhesion to the surface and prevents phase separation during baking [11]. Thus, wetting of coke by pitch is a physico-chemical process.

The important physical properties which influence wetting are surface roughness and porosity of coke and flow properties (softening point and viscosity) of pitch. On the other hand, the chemical interactions may be in the forms of acid-base, hydrogen bonding [11], electrostatic and covalent interactions.

Different techniques can be used to analyze the coke-pitch interaction.

\section{$\underline{\text { Scanning Electron Microscopy (SEM) }}$}

Scanning electron microscopy (SEM) is an important tool to visualize the surface texture of coke particles at nano-scale. SEM makes it easy to identify the size of pores and visualize their inner structural details in case of a small coke sample. It can also show how a coke surface is wetted by pitch, but it has an inherent limitation in sample size making it difficult to analyze large coke surfaces. Sample preparation is also a tedious job.

\section{Optical Microscopy}

Optical microscopy can prove to be an efficient technique to analyze larger surfaces compared to those used for SEM. By mosaic technique, it is possible to analyze around $2 \mathrm{~cm} \times 2 \mathrm{~cm}$ surfaces. The utilization of polarized light and custom made image analysis software for analyzing pores in coke [12-15] as well as the distribution of pitch $[16,17]$ and pore or crack $[18]$ in green anodes was reported in the literature.

\section{$\underline{\text { Image Analysis }}$}

Image analysis can be used to carry out a quantitative analysis of images taken with SEM or optical microscope. This analysis can give the surface composition (percentages of coke, pitch, and pores) of an anode sample or a granular coke (percentages of coke and pore) sample.

\section{$\underline{\text { X-Ray Photon Spectroscopy (XPS) }}$}

As wetting of coke with pitch is mainly a surface phenomenon, the distribution of the atoms and functional groups in coke and pitch surfaces is necessary. XPS spectra are obtained by irradiating a material with a beam of X-rays and simultaneously measuring the kinetic energy and the number of electrons that escape from the top 1 to $10 \mathrm{~nm}$ of the sample material. Thus XPS gives an idea about different atoms on the surface, nature of bonds [19] and their electronic states based on their binding energies. Chemical state analysis can identify and quantify functional groups [20] like $\mathrm{COOH}, \mathrm{C}=\mathrm{O}$, etc.

\section{$\underline{\text { Fourier Transform Infrared Spectroscopy (FTIR) }}$}

FTIR is an important tool to identify the functional groups [21] based on vibrational and rotational energies of the bonds. It can identify different $\mathrm{C}-\mathrm{H}$ bonds with different hybridizations of carbon which is difficult to analyze using XPS. It can easily distinguish aliphatic and aromatic hydrocarbons. The ratio of the different peak heights can be used as indexes to compare the activities of different samples. The aromaticity index, ortho substitution index [22] are important in analyzing the chemical characteristics of pitch and coke samples. Reflectance mode FTIR can also be used to study the functional groups at coke-pitch interface.

\section{$\underline{\text { X-Ray Diffraction (XRD) }}$}

Cokes used in fabrication of anodes are calcined at high temperatures (about 1100 to $1300^{\circ} \mathrm{C}$ ). The calcination condition influences the degree of graphitization and change in surface properties of coke (e.g. OH functional group). Thus the degree of graphitization gives an insight into the calcination condition of coke. As graphite is crystalline in structure, change in the degree of calcination will change the average crystallite length which can be measured by an XRD study.

\section{Extraction of Pitch Components using Different Solvents}

Various solvents can selectively extract compounds having specific functional groups. For example hexane can dissolve aliphatic compounds and not aromatic compounds; on the other hand, toluene is more selective towards aromatic compounds. Quinoline cannot dissolve very high molecular-weight compounds. Thus comparison of solubility in different solvents with FTIR analysis of soluble phase and the residue can give an indication of association of various functional groups with aliphatic or aromatic skeletons and distribution of different molecular weight compounds in a sample.

\section{Wettability}

Wettability is the measure of an extent of contact between solid and liquid. It could be chemical (reaction at solid-liquid interface) or physical due to intermolecular forces (adhesive and cohesive forces). Wetting is characterized by the contact angle which is the angle between the gas-liquid interface and solid-liquid interface. The wettability increases with decreasing contact angle. Contact angle decreases with increasing temperature and time. Static or dynamic contact angles can be measured with the infiltration method where the liquid is pushed through a solid bed with a known force [23] or with the sessile-drop method where a drop of liquid is placed on a solid bed. For coke-pitch pair, the sessile-drop method is generally used [5] since pushing pitch through a coke bed composed of fine coke particles proves to be difficult. An inert atmosphere is maintained inside the equipment. The contact angle is determined from the image of the drop. This experiment gives an idea of variation of wettability with time and temperature as well as helps compare the wettability of different coke-pitch systems under similar conditions.

\section{Computed Tomography (CT)}


SEM and optical microscopy are used to analyze the surfaces. However, tomography can be used to study the whole volume of an object from a series of 2D X-ray images. This nondestructive method allows the investigation of the internal structure (cracks, pores, etc.), homogeneity and density profile of anodes [24, 25].

Thus, SEM, optical microscopy and image analysis can analyze physical texture and pores of a coke sample. XRD can give an indication of the degree of calcination of coke which in turn can give an idea of the physical and chemical modifications of the coke surface. On the other hand, XPS and FTIR can give information on atoms and functional groups in coke and pitch. XPS and FTIR analysis results are complementary to each other. XPS helps identify the surface functional groups whereas FTIR analyzes the overall availability of different functional groups. All this information helps determine the possibility of hydrogen bonding ( $\mathrm{H}$ attached to strongly electronegative atoms such as $\mathrm{N}, \mathrm{O}$ in one material and strongly electronegative atoms in another material), electrostatic interaction (pi electron cloud of aromatic ring of one material with positively charged center of other material), covalent bonding (presence of electronegative atoms such as $\mathrm{O}, \mathrm{N}, \mathrm{S}$ ). Solvent extraction gives additional information on molecular weights of different compounds and association of different functional groups to aliphatic or aromatic structures in pitch. If a material has a very high percentage of large molecules, it can provide steric hindrance during bond formation which can reduce coke-pitch interactions.

SEM (JEOL-JSM-6480LV) and optical microscope (Nicon Eclipse ME 600P) were used to capture images of polished green anode/coke surfaces for analysis. An image analysis software was developed to determine different components (coke, pore) of coke and anode (coke, pitch, pores/cracks) using the Matlab image analysis toolbox. It is difficult to distinguish these components using commercially available image analysis software due to the similarity of colors of different components. First the shadows were eliminated. Then the different phases (pore/crack, pitch, and coke) were identified by applying different threshold conditions. The different phases were finally marked by different colors such as pore/crack by black, coke by red, and pitch by green. The amount of each phase was calculated based on the number of pixels of that phase in the picture. AXIS XPS (Ultra XPS spectrometer, Kratos Analytical) analyses were carried out at the Alberta Centre for Surface Engineering and Science (ACSES) of the University of Alberta. FTIR (Perkin Elmer, spectrum one) analysis was carried out using the reflectance technique. Solvent extraction was performed by keeping a mixture of a sample and a solvent in a container for two hours in an ultrasonic bath vibrating at $20 \mathrm{kHz}$. The wetting experiments were performed in a sessile-drop system. A drop of molten pitch was dropped on a small coke bed and the change in geometry of the drop was monitored using a digital video camera (APPRO, model KC). From the images, the contact angle of the drop was determined at different times using FTA32 software. CT scanner (Skyscan, 1172) was used to scan anode samples.

An extensive study was carried out on the effects of different physical and chemical properties on coke-pitch interaction. Below, a number of examples are presented for the application of the above techniques.
Figure 1 shows the SEM picture of a coke sample. The presence of cracks and pores on the coke surface are evident. The dimensions of some pores are very small whereas some have larger dimensions. The very small pores prevent the penetration of pitch into coke particles [26]. Thus, the presence of small pores in coke samples $(<0.5 \mu \mathrm{m})$ in large quantity reduces the extent of wetting and cokepitch interaction.

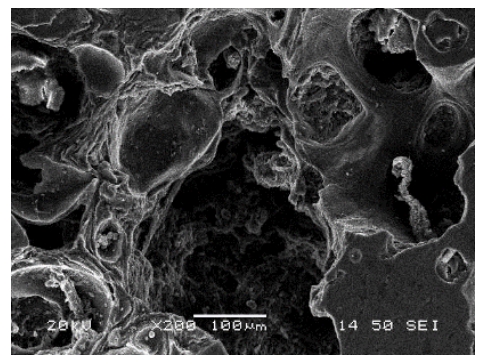

Figure 1: SEM Image of Coke Surface

Figure 2 shows the application of an image analysis technique to an optical microscope image of coke to identify the percentage of pores/cracks on the coke surface.

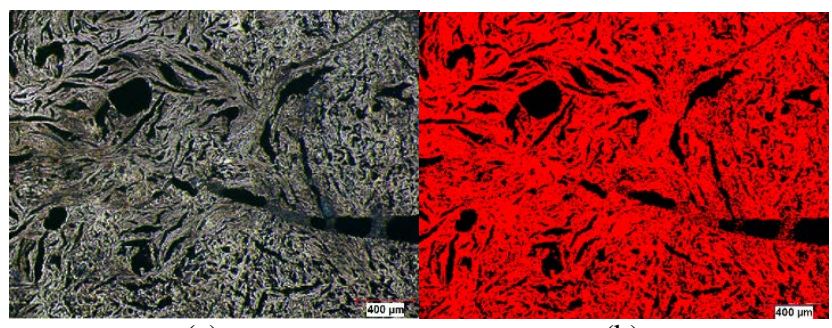

(a)

(b)

Figure 2 : Optical Microscope Image of a Coke Surface (a) Original, (b) Processed (red: coke; black: pore)

Image analysis technique can help the visualization of the distribution of pitch and pores/cracks on an anode surface (see Figure 3,4). The distribution and the thickness of the pitch layer have an important impact on binding coke particles together and consequently on crack formation as well as on electrical, thermal, and mechanical properties of anode.

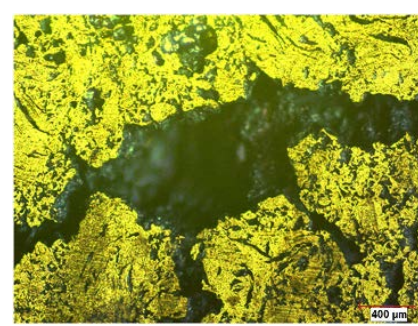

(a)

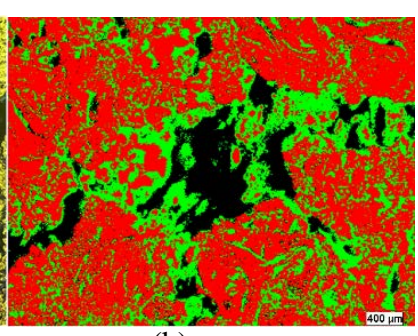

(b)
Figure 3: Optical Microscope Image of Anode Sample with Pore (a) Original with Polarized Light (b) Processed (red: coke; black: pore; green: pitch)

With the image analysis software developed, it is possible to isolate and analyze any component (coke, pitch, pore/crack). Figure 4(c) shows isolated coke particles (white) of anode sample..

(a)

(b)

\section{Results and Discussion}




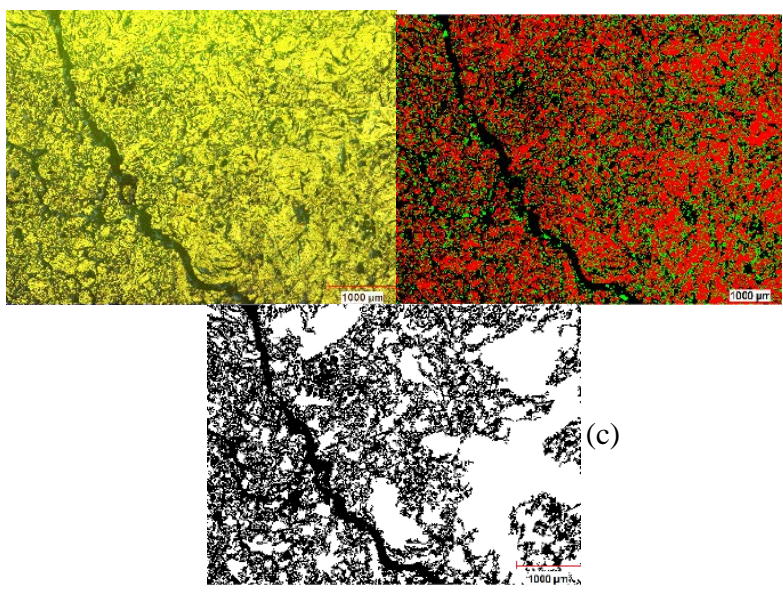

Figure 4: Optical Microscope Image of an Anode Sample with Cracks (a) Original with Polarized Light, (b) Processed (red: coke; black: pore and crack; green: pitch) (c) Isolated Coke Particles (white)

Table 1 shows XPS analysis of the coke sample shown in Figure 2. Figure 5 shows the analysis of different functional groups after deconvoluting $\mathrm{C}-1 \mathrm{~s}$ binding energy information for the coke illustrated in Figure 2 and a pitch sample. Thus, the XPS study of coke and pitch reveals the presence of different functional groups. In the example given in Figure 5, both coke and pitch have $\mathrm{O}, \mathrm{N}$, and $\mathrm{S}$ containing functional groups which can favor the formation of hydrogen bonding during the wetting of coke by pitch and reinforce the carbon-pitch interaction.

Table 1: Results of the XPS Analysis of Coke (shown in Figure 2) and Pitch

\begin{tabular}{|c|c|c|c|c|c|c|c|c|c|}
\hline \multirow[t]{2}{*}{$\begin{array}{c}\text { Sample } \\
\text { Type }\end{array}$} & \multirow[t]{2}{*}{$\begin{array}{c}C \\
(\%) \\
\end{array}$} & \multicolumn{5}{|c|}{ Carbon components } & \multirow[t]{2}{*}{$\begin{array}{c} \\
(\%)\end{array}$} & \multirow[t]{2}{*}{$\begin{array}{c}N \\
(\%)\end{array}$} & \multirow[t]{2}{*}{$\begin{array}{c}S \\
(\%) \\
\end{array}$} \\
\hline & & $\begin{array}{l}\text { C-C/ } \\
\text { C-H }\end{array}$ & $\begin{array}{l}\text { C-N/ } \\
\text { C-O }\end{array}$ & $\begin{array}{l}\mathrm{COH} / \\
\mathrm{COC}\end{array}$ & $C=0$ & $\mathrm{COO}$ & & & \\
\hline Coke & 93.52 & 53.45 & 38.23 & 6.31 & 2.01 & & 3.55 & 0.85 & 2.08 \\
\hline Pitch & 97.07 & 34.04 & 45.26 & 13.4 & 3.64 & & 1.53 & 1.32 & 0.08 \\
\hline
\end{tabular}

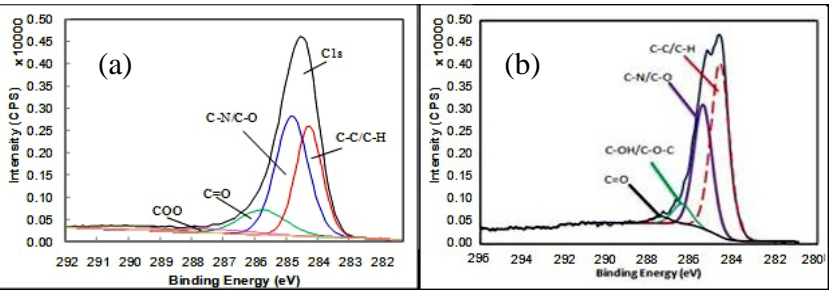

Figure 5: XPS Spectra of (a) Coke Sample in Figure 2 and (b) Pitch Sample

Figure 6 shows the FTIR analysis of the same pitch and coke above. It also shows the formation of bonds at the interface during coke and pitch contact. FTIR analysis shows the presence of aliphatic (2850-3000 $\left.\mathrm{cm}^{-1}\right)$ and aromatic (3000-3100 $\mathrm{cm}^{-1}$ ) carbon, C-N/CO (1200-1300 cm-1), C-O stretch for ester/ ether/alcohol (950-1150 $\left.\mathrm{cm}^{-1}\right)$, substituted aromatic C-H $\left(700-900 \mathrm{~cm}^{-1}\right)$ in both coke and pitch. This shows the possibility of formation of electrostatic as well as hydrogen bonds during wetting. Before contact, the peaks appear more discrete which suggests the presence of functional groups of specific range of molecular weight. However, after contact, the discrete peaks disappear and diffused peaks appear. This suggests the formation of new bonds of different ranges of molecular weight. This may take place between coke and pitch, and also, during heating, some molecules may undergo modifications such as condensation, bond cleavage, etc.

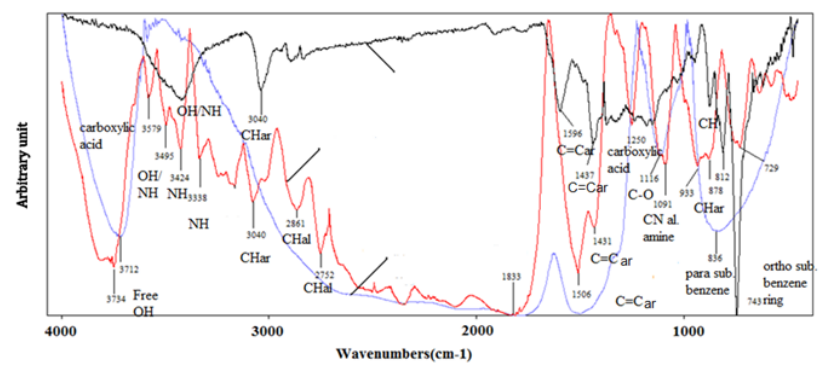

Figure 6: FTIR Spectra of Coke (blue) and Pitch (black) at Room temperature and Their Mixture (red) at Mixing Temperature

The average crystalline length, $\mathrm{Lc}$, for the coke was measured using $\mathrm{XRD}$. The values depend on the calcination temperature of coke. For a similar degree of calcination, this value is usually similar for different cokes. As reported in the literature, reactivity, therefore, dusting decreases as the crystalline length of coke decreases due to the reduction of the difference between the reactivities of coke and pitch [4]. It is also reported in the literature that the calcination temperature affects the wettability of coke by pitch. It was found that with increasing calcination temperature, the complete wetting temperature increases, thus, the wettability of coke decreases [27]. Figure 7 illustrates the determination of $\mathrm{L}_{\mathrm{c}}$ for a coke sample from XRD analysis.

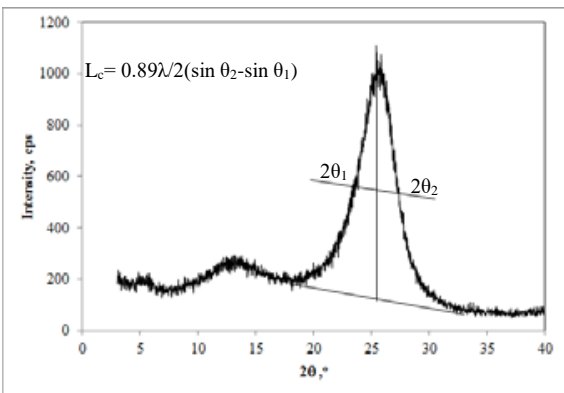

Fig 7: Determination of Crytalline Length $\left(\mathrm{L}_{c}\right)$ of Coke (the line between the $2 \theta_{1}$ and $2 \theta_{2}$ is the full-width at the half-maximum height of the peak, $\lambda$ is the wavelength, $\theta$ is the angle of diffraction)

Different solvents (quinoline, toluene, hexane, methanol) were used to analyze the extent of solubility of the pitch sample. Table 2 gives an example for the solubility of one pitch in different solvents as well as the types of chemical components which are soluble in a particular solvent. Usually quinoline and toluene insolubles are reported as pitch properties. Pitch contains solid particles which are insoluble in quinoline (QI), a very strong solvent. There are two types of quinoline insolubles. While primary QI is beneficial 
( $\mathrm{C} / \mathrm{H}>3.5$ ), the secondary one (mesophase, $\mathrm{C} / \mathrm{H}<3$ ) is either neutral or detrimental for coke-pitch interactions. The difference between toluene insolubles (TI) and QI is called $\beta$-resin which facilitates coke-pitch bonding [28].

Table 2: Solubility of Pitch in Different Solvents

\begin{tabular}{|c|c|l|}
\hline Solvent & $\begin{array}{c}\text { Solubility } \\
\text { (\%) }\end{array}$ & \multicolumn{1}{c|}{ Remarks } \\
\hline Quinoline & 87.9 & $\begin{array}{l}\text { It dissolves all but high molecular weight aromatic compounds. } \\
\text { Insoluble part (QI) can cause steric hindrance during wetting. } \\
\text { On the other hand this high molecular weight fraction increases } \\
\text { extent of carbonization during baking. Higher the QI, higher is } \\
\text { the coking value }\end{array}$ \\
\hline Hexane & 784 & $\begin{array}{l}\text { The lower the hexane solubles are, the lower the amount of } \\
\text { aliphatic chains is. As aliphatic chains have low C/H ratio, high } \\
\text { value of hexane soluble is not preferred for wetting }\end{array}$ \\
\hline Methanol & 8.24 & $\begin{array}{l}\text { Methanol solubility gives idea about presence of polar groups } \\
\text { which is desirable for hydrogen bonding. But high value of } \\
\text { methanol solubility also shows increase in aliphatic chains which } \\
\text { is not desirable. }\end{array}$ \\
\hline Toluene & 56.63 & $\begin{array}{l}\text { Toluene solubility gives idea about aromatic compounds of } \\
\text { medium molecular weight range which is desirable for wetting. }\end{array}$ \\
\hline
\end{tabular}

The sessile drop experiment results for two cokes with the same pitch are shown in Figure 8. The wettability increases (contact angle decreases) with time for both cokes. The Coke 2 is more suitable for the pitch used since it has lower contact angles. These data might also give an idea about the mixing time required for the coke to be wetted as much as possible for a given system.

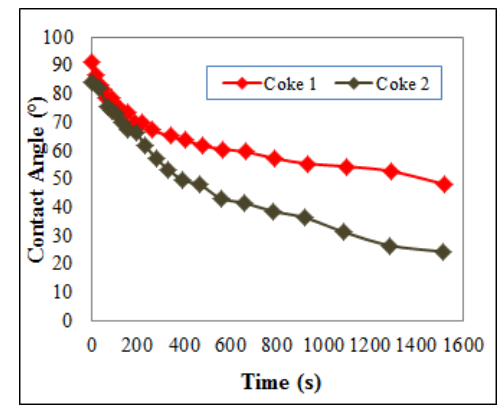

Figure 8: Contact angle vs. Time Data for Two Cokes with the Same Pitch

The sessile-drop can be cut vertically for further analysis. Figure 9 shows the SEM image of a coke-pitch interface. It is possible to see from this figure the extent of pitch penetration among the coke particles. As seen from this figure, pitch entered between the coke particles for this particular coke-pitch pair. This method can serve to identify underpitching and overpitching problems.

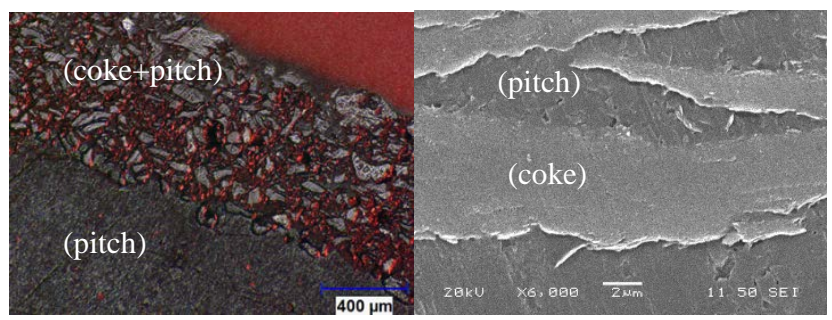

(a)

(b)

Figure 9: Image of the Coke-Pitch Interface of a Sessile-Drop Using (a) Optical microscope and (b) SEM

Figure 10 presents two of the series of $2 \mathrm{D}$ images at the top and the bottom of an anode sample taken with CT scanner. The cracks and pores can clearly be seen from this figure. This technique allows the visualization of the whole sample.

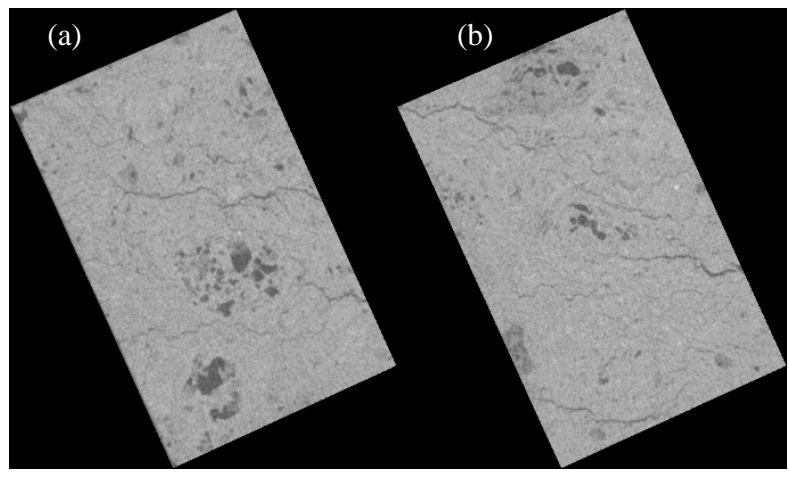

Figure 10: 2D X-ray Images of (a) Top (b) Bottom Surfaces of Anode Sample

\section{Conclusions}

Coke-pitch interactions are one of the important factors affecting the final anode properties. Different techniques (SEM, optical microscopy, image analysis, XPS, XRD, solvent extraction, wettability measurements, etc.) can be successfully used to obtain information on these interactions, and, consequently, on the compatibility of a given coke with a given pitch.

\section{Acknowledgements}

The technical and financial support of Aluminerie Alouette Inc as well as the financial support of the Natural Sciences and Engineering Research Council of Canada (NSERC), Dévelopment économique Sept-Îls, Université du Québec à Chicoutimi (UQAC) and Foundation of Université du Québec à Chicoutimi (FUQAC) are greatly appreciated.

\section{References}

1. A. I. Berezin, P.V. Polaykov, O. O.Rodnov, V.A. Klykov, V.L. Krylov, "Improvement of green anodes quality on the basis of the neural network model of the carbon plant workshop”, Light Metals, (2002), 605-608.

2. R. Fernandez, "Petroleum coke, grades and production", CarboMat seminar Trondheim, (2003).

3. N.A Adams, "Characterization on pitch wetting and penetration behaviour of petroleum coke and recycled butts in prebake carbon anode”, (Ph.D thesis, The Pennsylvania State University, University Park, 2004).

4. C-L. Lagacé, M-J. Chollier-Brym, A. Gagnon, C. Boulanger, D. Lepage, G. Savard, G. Bouchard, A. Charrette , "Anode Reactivity : Effect of Anode Calcination Level”, Light Metals, (2009), 905-908.

5. A. A. Mirchi, G. Savard, J.P. Tremblay, M.Simard, “Alcan characterisation of pitch performance for pitch binder evaluation and process changes in an aluminium smelter", Light metals, (2002), 525-534.

6. J. Lahaye, P. Ehrburger, "Pitch-coke interactions", Fuel, 64(9) (1985), 1187-1191. 
7. P. Couderc, P. Hyvernat, J. Lemarchand, "Correlations between ability of pitch to penetrate coke and the physical characteristics of prebaked anodes for the aluminium industry", Fuel, 65(2) (1986), 281-287.

8. V. G. Rocha, C. Blanco, R. Santamaria, E.I. Diestre, R. Menedez, M. Granda, "Pitch/coke wetting behaviour", Fuel, 84(2005), 1550-1556.

9. V.G. Rocha, C. Blanco, R. Santamaria, E.I. Diestre, R. Menendez, M. Granda, "An insight into pitch/substrate wetting behaviour. The effect of the substrate processing temperature on pitch wetting capacity", Fuel, 86(7-8) (2007), 1046-1052.

10. V.G. Rocha, C. Blanco, R. Santamaria, E.I. Diestre, R. Menendez, M. Granda, "The effect of the substrate on pitch wetting behaviour", Fuel Processing Technology, 91(11) (2010), 1373-1377.

11. U. Suriyapraphadilok, "Characterization of Coal- and Petroleum-derived Binder Pitches and the Interaction of Pitch/coke Mixtures in Pre-baked Carbon Anodes”, (Ph.D. thesis, Pennsylvania state university, 2008)

12. G. L. Qiao, S. Eser, "Automated Digital Image Analysis of Semi-coke Texture”, 23'd Biennial Conj on Carbon, University Park, Pennsylvania, (1997)

13. S. C. Greeff, W.H. Smith, "Automated coke petrography”, APCOM 87, Proceedings of the Twentieth International Symposium on the Application of Computers and Mathematics in the Mineral Industries, Metallurgy. Johannesburg, 2 (1987), 253 - 262.

14. S.Rørvik, H.A. Øye, M. Sørlie, "Characterization of Porosity in Cokes by Image Analysis”, Light Metals, (2001), 603-612

15. R. Bowers, S. Ningileri, D. C. Palmlund, B. Vitchus, F.Cannova, "New Analytical Methods to Determine Calcined Coke Porosity, Shape, and Size”, Light Metals, (2008), 875880

16. A. N. Adams, J. P. Mathews, H. H. Schobert, "The Use of Image Analysis for the Optimization of Pre-baked Anode Formulation”, Light Metals, (2002), 545-552.

17. S. Rørvik, A. P. Ratvik, T. Foosnæs, "Characterization of Green Anode Materials by Image Analysis”, Light Metals, (2006), 553-558.

18. B. A. Sadler, "Diagnosing Anode Quality Problems Using Optical Microscopy”, Light Metals, (2012), 1289-1292.

19. H. Estrade-Szwarckopf, "XPS Photoemission in Carbonaceous Materials: A 'Defect' Peak Beside the Graphitic Asymmetric Peak”, Carbon, 42 (2004), 1713-1721.

20. T. Metzinger, K. J. Huttinger, "Investigations on the Crosslinking of Binder Pitch Matrix of Carbon Bodies with Molecular Oxygen - Part I. Chemistry of Reactions Between Pitch and Oxygen”, Carbon, 35(7) (1997), 885-892
21. J. A. Menéndez, J. J. Pis, R. Alvarez, C. Barriocanal, E. Fuente, and M. A. D1'ez, "Characterization of Petroleum Coke as an Additive in Metallurgical Cokemaking. Modification of Thermoplastic Properties of Coal”, Energy \& Fuels, 10 (1996), 1262-1268.

22. M. D. Guillén, M. J. Iglesias, A. Domínguez,C. G. Blanco, "Semiquantitative FTIR Analysis of a Coal Tar Pitch and Its Extracts and Residues in Several Organic Solvents," Energy \& Fuels, vol. 6, pp. 518-525, 1992.

23. D. Kocaefe, G. Ergin, G., Y. Kocaefe, "Determining the Wettability of Granular Alumina by Aluminum-Magnesium Alloys Using the Infiltration Method”, (2008), Surface and Interface Analysis, 40(12), 1516-1522,

24. A. N. Adams, O. Karacan, A. Grader, J.P. Mathews, P.M. Halleck, H.H. Schobert, "The Non-Destructive 3-D Characterization of Pre-Baked Carbon Anodes Using X-Ray Computerized Tomography”, Light Metals, (2002), 535-539.

25. D. Picard, H. Alamdari, D. Ziegler, P-O. St-Arnaud, M. Fafard. "Characterization of a Full-Scale Prebaked Carbon Anode Using X-Ray Computerized Tomography”. Light Metals, (2011), 973-978.

26. D. Belitskus, D.J. Danka, “A Comprehensive Determination of Effects of Calcined Petroleum Coke Properties on Aluminum Reduction Cell Anode Properties”, Light Metals, (1989), 429-442.

27. E. A. Heintz, "Wetting of Filler by Binder - a Simple Apparatus for Determining Wetting Temperatures”, Carbon, 24 (1986), 131-134.

28. K.L. Hulse, “Anode Manufacture: Raw Materials,Formulation and Processing Parameters", (Sierre, Switzerland, R\&D Carbon, 2000), 101-102. 